\title{
Is parent-child bed-sharing a risk for wheezing and asthma in early childhood?
}

\author{
Maartje P.C.M. Luijk ${ }^{1-3}$, Agnes M.M. Sonnenschein-van der Voort ${ }^{3-5}$, \\ Viara R. Mileva-Seitz ${ }^{1,3}$, Pauline W. Jansen ${ }^{2,6}$, Frank C. Verhulst ${ }^{2}$, \\ Albert Hofman ${ }^{4}$, Vincent W.V. Jaddoe ${ }^{3,4,7}$, Johan C. de Jongste ${ }^{7}$, \\ Marinus H. van IJzendoorn ${ }^{1,8}$, Liesbeth Duijts ${ }^{3-5,9}$ and Henning Tiemeier $2,4,10$
}

Affiliations: 'School of Pedagogical and Educational Sciences, Erasmus University Rotterdam, Rotterdam, The Netherlands. ${ }^{2}$ Dept of Child and Adolescent Psychiatry/Psychology, Erasmus University Medical Center, Rotterdam, The Netherlands. ${ }^{3}$ The Generation R Study Group, Erasmus University Medical Center, Rotterdam, The Netherlands. ${ }^{4}$ Dept of Epidemiology, Erasmus University Medical Center, Rotterdam, The Netherlands. ${ }^{5}$ Dept of Pediatrics, Division of Respiratory Medicine, Erasmus University Medical Center, Rotterdam, The Netherlands. ${ }^{6}$ Institute of Psychology, Erasmus University Rotterdam, Rotterdam, The Netherlands. ${ }^{7}$ Dept of Pediatrics, Erasmus University Medical Center, Rotterdam, The Netherlands. ${ }^{8}$ Center for Child and Family Studies, Leiden University, Leiden, The Netherlands. ${ }^{9}$ Dept of Pediatrics, Division of Neonatology, Erasmus University Medical Center, Rotterdam, The Netherlands. ${ }^{10}$ Dept of Psychiatry, Erasmus University Medical Center, Rotterdam, The Netherlands.

Correspondence: Maartje P.C.M. Luijk, School of Pedagogical and Educational Sciences, Erasmus University Rotterdam, PO Box 1738, 3000 DR Rotterdam, The Netherlands. E-mail: luijkafsw.eur.nl

ABSTRACT Household crowding can place young children at risk for respiratory infections which subsequently provoke asthma symptoms. However, crowding might also protect against asthma, in accordance with the hygiene hypothesis. We tested if parent-infant bed-sharing, an important dimension of household crowding, increases or decreases the risk for asthma.

In a population-based prospective cohort $(\mathrm{N}=6160)$ we assessed bed-sharing at 2 and 24 months; wheezing between 1 and 6 years of age; and asthma at 6 years of age. Generalised estimating equation models were used to assess repeated measures of wheezing and asthma.

We found no association between bed-sharing in early infancy and wheezing or diagnosis of asthma. By contrast, we found a positive association between bed-sharing in toddlerhood and both wheezing (OR 1.42 , 95\% CI 1.15-1.74) and asthma (OR 1.57, 95\% CI 1.03-2.38). Wheezing was not associated with bedsharing when using cross-lagged modelling.

This study suggests that bed-sharing in toddlerhood is associated with an increased risk of asthma at later ages, and not vice versa. Further studies are needed to explore the underlying causal mechanisms.

@ERSpublications

More wheezing and asthma reported for bed-sharing toddlers, not for infants: parental vigilance or increased risk? http://ow.ly/Dgy4v

For editorial comments see Eur Respir J 2015; 45: 596-600 [DOI: 10.1183/09031936.00234814].

A press release for this article is available from erj.ersjournals.com/site/misc/presspack.xhtml

This article has supplementary material available from erj.ersjournals.com

Received: March 032014 | Accepted after revision: Oct 102014 | First published online: Dec 102014

Conflict of interest: Disclosures can be found alongside the online version of this article at erj.ersjournals.com

Copyright @ERS 2015 


\section{Introduction}

Crowded household conditions place young children at risk of acute lower respiratory infections [1-3], or increased severity of such infections [4]. This is potentially due to a higher viral load, either through interpersonal transmission or through contact with more infectious particles [5]. However, crowding may also protect against asthma [6]. According to the hygiene hypothesis, viral infections transmitted by older siblings could protect young children from allergic diseases, and particularly those of the respiratory tract [7-9]. Parent-infant bed-sharing at night-time has not been explored in relation to asthma symptoms in childhood. Importantly, bed-sharing can occur even in the absence of crowding, and thus represents a unique dimension of proximity to others that potentially transects socioeconomic variables.

In early infancy and, thus, prior to the development of wheezing symptoms, parents initiate bed-sharing for a number of reasons, including ease of breastfeeding and cultural values [10,11]. Later on, parents may adopt bed-sharing practices that allow for closer monitoring of their already asthmatic children [12], as asthma symptoms are frequently experienced during night-time hours. Asthma symptoms exacerbate during the night due to changes in serum cortisol and inflammatory mediators, sleep posture, and increased allergen exposure [12]. Indeed, in some studies asthma has been associated with increased sleep problems in children [13, 14]. Thus, asthma could stimulate bed-sharing beyond early infancy because of sleep disordered breathing and frequent awakenings at night. It is, therefore, important to capture both early and later bed-sharing practices. A recent review [12] suggested that research should focus on direction of the effects between sleep and asthma, with accurate diagnosis of asthma, large sample sizes, inclusion of ethnic minorities, and assessment of crowding and sleep routines such as bed-sharing. In a large-scale, multi-ethnic prospective study, we try to disentangle the reciprocal effects of bed-sharing and asthmatic symptoms in young children, by longitudinally testing the hypotheses that bed-sharing practices may increase the development and persistence of asthmatic symptoms or that asthmatic symptoms may stimulate bed-sharing practices. Both bed-sharing and asthma were repeatedly measured throughout childhood.

\section{Materials and methods}

Design

This study was embedded in the Generation R Study, a population-based prospective cohort from early fetal life onwards in Rotterdam, the Netherlands [15]. The study has been approved by the Medical Ethical Committee of the Erasmus Medical Centre in Rotterdam. Written informed consent was obtained from all participants. A total of 6160 mothers and their children were included in the current analyses.

\section{Respiratory symptoms}

Information on wheezing (no/yes) was obtained by questionnaires, which were adapted from the International Study on Asthma and Allergy in Childhood (ISAAC) [16] at the ages of 1, 2, 3, 4 and 6 years. For this analysis, we defined asthma-like symptoms as any reported wheezing in a given year [17]. All children included in the analyses were assessed at least twice and response rates for the questionnaires varied from $71 \%$ to $76 \%$ [18]. Wheezing patterns were created to assess persistence of wheezing over time, using three patterns: early-only wheezing (wheezing reported at ages 1, 2 and/or 3 years), late-only wheezing (reported at ages 4 and/or 6 years), and persistent wheezing (reported at all ages between 1 and 6 years) [19]. Information on physician-diagnosed asthma was obtained by maternal report at 6 years of age.

\section{Bed-sharing}

We assessed sleeping practices at 2 and 24 months using a parental questionnaire relating to the place of sleep of the child [20]. Bed-sharing was defined as the child sharing a bed with the mother (or both parents). At 2 months the question was "How often does the child sleep in the parents' bed?" and an answer of more than three times a week was considered bed-sharing. At 24 months the question was "Where does the child sleep?" with answer options being in their own bed or in the parents' bed [11].

Support statement: The general design of the Generation R Study was made possible by financial support from the Erasmus Medical Center, Rotterdam, the Erasmus University Rotterdam and the Netherlands Organization for Health Research and Development. The present study was supported by additional grants from the Netherlands Organization for Scientific Research: grant number 017.106.370 (NWO ZonMW VIDI) to H. Tiemeier, and the NWO SPINOZA prize to M.H. van IJzendoorn. A. Sonnenschein-van der Voort is the recipient of a European Respiratory Society Fellowship (STRTF 93-2012) and received a grant from the Ter Meulen Fund, Royal Netherlands Academy of Arts and Sciences (TMF2012/228).V. Jaddoe received an additional grant from the Netherlands Organization for Health Research and Development (ZonMw-VIDI). L. Duijts received funding from a European Respiratory Society/Marie Curie Joint Research Fellowship (number: MC 1226-2009, grant agreement: RESPIRE, PCOFUND-GA-2008-229571), and the Lung Foundation Netherlands (number: $3.2 .12 .089 ; 2012$ ). None of the authors had a financial or personal conflict of interest related to the content of the study. 


\section{Covariates}

Information on maternal age, parity, ethnicity, socioeconomic status, history of asthma or atopy, and pet keeping was obtained by questionnaires completed by the mother during pregnancy. Child ethnicity was based on the country of birth of the parents. Socioeconomic status was assessed using the highest maternal educational level. Information on maternal psychological distress was obtained by postal questionnaires at 20 weeks of gestation using the Brief Symptom Inventory [21]. Data on active maternal smoking was collected using questionnaires sent by mail in the first, second and third trimesters of pregnancy and combined into a single parameter as smoking (no/yes). Postal questionnaires at the ages of 6 and 12 months postpartum provided information about breastfeeding and day care attendance, and at 18 months child sleep problems were assessed using the Child Behavior Checklist (CBCL) [22] for toddlers (e.g. nightmares, too much or little sleep, overtired). Questionnaires between the ages of 1 and 6 years assessed occurrence of lower respiratory tract infections (pertussis, bronchitis, bronchiolitis or pneumonia) and doctor attended inhalant allergy [15]. Gestational age at birth and sex of the children were obtained from midwife and hospital registries (fig. 1).

\section{Statistical analysis}

We analysed the associations of bed-sharing with wheezing between the ages of 1 and 6 years using generalised estimating equation models (GEEs). With GEE analyses, repeatedly measured symptoms over time can be analysed, taking into account that these repeated measurements within the same subject are correlated. For the analysis examining effects of bed-sharing at 2 months, wheezing between the ages of 1 and 6 years was used as the outcome measure; for the analysis examining effects of bed-sharing at 24 months, wheezing at 3-6 years of age was used as the outcome. Multinomial regression analysis was used to assess the relationship between bed-sharing and wheezing patterns. Wheezing patterns (early-only wheezing, late-only wheezing and persistent wheezing) were based on MArTinez et al. [19]. Logistic regression analysis was used to assess the association between bed-sharing and physician-diagnosed asthma. A cross-lagged modelling approach was applied to estimate reciprocal influences [23] between bed-sharing and wheezing within one model. The model included multiple logistic regressions, reflecting associations of bed-sharing at 2 months of age with wheezing at 1 year, bed-sharing at 2 years with wheezing at 2, 3, 4 and 6 years, and wheezing at 1 year with bed-sharing at 2 years, while simultaneously accounting for continuity in bed-sharing and wheezing over time.

To reduce bias associated with missing data, missing values of the covariates and the outcome were multiply imputed based on the correlation of the missing variables with all other variables in the analyses,

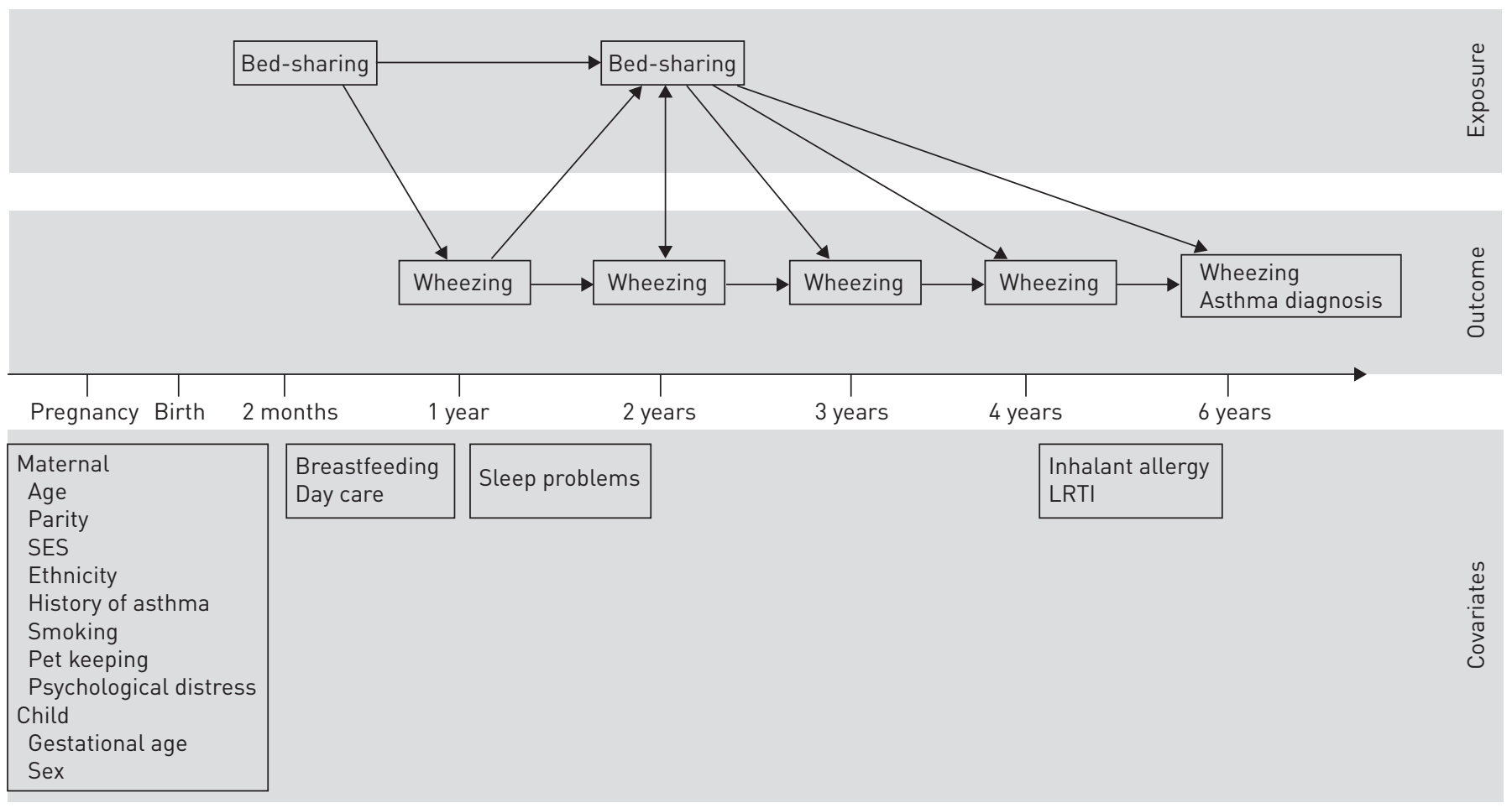

FIGURE 1 Assessments and model of the study. SES: socioeconomic status; LRTI: lower respiratory tract infection. 
i.e. predictors, covariates and outcomes, and additionally with educational level, smoking and age of the father. Data were imputed for participants with two or more assessments of wheezing. 25 imputed datasets were created and analysed separately after which the results were pooled [24]. Characteristics for study participants in both the original and imputed datasets are presented in table 1. All models were initially performed unadjusted and subsequently adjusted for potential confounders. Selection of confounders was based on previous studies [25-27], if they were associated with both the determinant and outcome, or changed the effect estimate by $>10 \%$ when added to the basic model. In the first adjusted model, the following confounders were included: child sex and age, maternal educational level and smoking. In the second adjusted model, additional confounders were entered: maternal body mass index (BMI), breastfeeding, parity, child ethnicity, gestational age at birth, day care attendance, pet keeping, maternal history of atopy and asthma, and maternal prenatal psychological distress. The models for 24 month bed-sharing were controlled for bed-sharing at 2 months. In a secondary analysis, the effects of child inhalant allergy, lower respiratory tract infections (LRTIs) and sleep problems were tested by adding them to the model in a last step. The statistical analyses were performed using the SPSS version 20.0 for Windows (IBM Corp., Armonk, NY, USA), SAS 9.2 (SAS institute, Cary, NC, USA) and Mplus version 7.11 (Muthén \& Muthén, Los Angeles, CA, USA) using Monte Carlo integration techniques and maximum likelihood estimation with robust standard errors.

\section{Results}

Sample characteristics

Children included in the present analysis $(\mathrm{n}=6160)$ (online supplementary material) had mothers who were older ( $\mathrm{t}$-test $-18.70 ; \mathrm{p}<0.001$ ) and had a higher educational level (Chi-squared 389.71; $\mathrm{p}<0.001$ ), were more often of European descent (Chi-squared 481.56; $\mathrm{p}<0.001$ ), smoked less during pregnancy (Chi-squared 67.94; $\mathrm{p}<0.001$ ), and were more often nulliparous (Chi-squared 55.14; $\mathrm{p}<0.001$ ), compared with those who did not provide information on bed-sharing and wheezing $(n=1536)$. No differences in maternal history of atopy and asthma were found (Chi-squared $<0.01 ; \mathrm{p}=0.96$ ).

Of the study participants, $18.5 \%(n=1141)$ of children shared a bed with their parents at 2 months of age, and $9.8 \%(n=605)$ were bed-sharers at 24 months of age. Bed-sharing at 2 and 24 months were positively correlated $(\mathrm{r}=0.22, \mathrm{p}<0.001)$. Wheezing prevalence among the children was $30.0 \%, 20.8 \%, 13.9 \%, 14.3 \%$ and $9.8 \%$ at ages 1,2,3, 4 and 6 years, respectively. According to the ages at which wheezing occurred, we grouped the children in the following way: $54.1 \%$ of children were classified as "never wheezing", $27.6 \%$ as having "early wheezing" (wheezing only at 1, 2 and 3 years of age), $4.8 \%$ as having "late wheezing" (wheezing only at 4 and 6 years of age) and 13.5\% as having "persistent wheezing" (wheezing at all ages between 1 and 6 years). Prevalence of physician-diagnosed asthma at 6 years of age was $8.0 \%$. Correlations between mother-reported wheezing and physician-diagnosed asthma increased from 1 to 6 years, the respective $r$-values were $0.20,0.26,0.33,0.33$, and 0.41 . Bed-sharing was positively associated with child sleep problems $(\mathrm{r}=0.30 ; \mathrm{p}<0.01)$.

Compared with solitary sleepers, children sharing a bed with their parents at 2 months of age did not have increased odds of wheezing between 1 and 6 years of age (fully adjusted model OR 0.98, 95\% CI 0.891.08) (table 2). Children had increased odds of wheezing between 3 and 6 years of life when they shared a bed at 24 months of age (OR 1.42, 95\% CI 1.15-1.74). Similarly, in analyses with wheezing patterns as an outcome, the results indicated that bed-sharing at 2 months was not associated with any wheezing pattern. However, bed-sharing at 24 months was significantly associated with persistent wheezing. This effect remained significant after controlling for maternal educational level, age, smoking during pregnancy and sex of the child in model 1, and additionally for bed-sharing at 2 months, maternal BMI, breastfeeding, parity, child ethnicity, gestational age at birth, day care attendance, pet keeping and maternal history of atopy, asthma and psychological distress in model 2 (OR 1.65, 95\% CI 1.17-2.35) (table 3).

Bed-sharing at 24 months, but not at 2 months, was significantly associated with physician-diagnosed asthma (unadjusted OR 1.99, CI 1.46-2.70) (table 3), and the effect remained significant after adjustment for confounders (OR 1.57, CI 1.03-2.38).

To assess the effect of child allergy, LRTI and sleep problems on the association between bed-sharing and asthma, these factors were added to the models in a secondary analysis. Child inhalant allergy, LRTI and sleep problems did not change the results for bed-sharing at 2 months in any of the analyses. For bed-sharing at 24 months, child LRTI did not change the effects. Child inhalant allergy, however, did attenuate the effect of bed-sharing at 24 months on asthma diagnosis (OR 1.31, 95\% CI 0.80-2.17), but not on the persistent wheezing pattern (OR 1.49, 95\% CI 1.01-2.20) or in the GEE analyses (OR 1.36, 95\% CI 1.07-1.72). The same was true for child sleep problems, which attenuated the effect of bed-sharing at 24 months only in the analysis of asthma diagnosis (OR 1.37, 95\% CI 0.89-2.09), but not in any of the other analyses. 
TABLE 1 Characteristics of children and their mothers ${ }^{\#}$

Original data

Imputed data

\section{Maternal characteristics}

Age years

$30.9 \pm 4.9$

$30.9 \pm 4.9$

Body mass index

$<20 \mathrm{~kg} \cdot \mathrm{cm}^{-2}$

$20-25.0 \mathrm{~kg} \cdot \mathrm{cm}^{-2}$

$25-30.0 \mathrm{~kg} \cdot \mathrm{cm}^{-2}$

$\geq 30 \mathrm{~kg} \cdot \mathrm{cm}^{-2}$

Missing

Education

Primary or secondary

Higher

Missing

History of asthma or atopy

No

Yes

$8.4(520)$

$49.6(3056)$

$22.3(1375)$

9.4 (581)

$10.2(628)$

44.8 (2757)

$49.3(3042)$

$5.9(361)$

$8.8(541)$

55.1 (3396)

26.5 (1633)

$9.6(590)$

Missing

Smoking during pregnancy

No

50.9 (3138)

31.6 (1947)

17.5 (1075)

Yes

$76.1(4690)$

$13.2(811)$

Missing

10.7 (659)

Psychological distress

No

$71.6(4410)$

5.7 (353)

Missing

$22.7(1397)$

48.5 (2987)

$51.5(3173)$

Parity

0

$55.5(3416)$

$\geq 1$

$41.5(2555)$

Missing

3.1 (189)

Gestational hypertensive problems $(\%)$

No

Yes

$83.9(5166)$

$5.2(322)$

Missing

$10.9(672)$

63.2 (3891)

36.8 (2269)

Gestational diabetes

No

Yes

Missing

$95.4(5876)$

$0.7(45)$

3.9 (239)

Child characteristics

Female sex

Gestational age at birth weeks

49.7 (3062)

$39.9 \pm 1.7$

$3451 \pm 550$

$85.2(5246)$

$14.8(913)$

Birth weight $\mathrm{g}$

Ethnicity

European

$68.1(4195)$

$28.2(1739)$

Non-European

Missing

3.7 (226)

Breastfeeding

Never

$7.6(470)$

Ever

$88.9(5478)$

Missing

$3.4(212)$

$92.3(5685)$

7.7 (475)

Day care attendance first year

No

29.2 (1798)

57.0 (3512)

43.0 (2648)

Yes

$42.0(2585)$

28.8 (1777)

Pet keeping

No

52.3 (3219)

26.6 (1639)

Missing

21.1 (1302)

$94.0(5792)$

$6.0(368)$

99.1 (6102)

0.9 (58)

49.7 (3062)

$39.9 \pm 1.7$

$3451 \pm 551$

$70.2(4322)$

29.8 (1838)

$8.0(491)$

$92.0(5669)$

$45.0(2771)$

55.0 (3389)

$66.3(4085)$

33.7 (2075)

Data are presented as mean $\pm \mathrm{SD}$, or $\%(n)$ for original data ( $\mathrm{N}$ range $=6159-4383$ ). ${ }^{\#}$ : $\mathrm{N}=6160$. 
TABLE 2 Associations of bed-sharing at 2 and 24 months with repeated wheezing assessments at age 1-6 years

\begin{tabular}{|c|c|c|c|c|c|c|}
\hline & \multicolumn{5}{|c|}{ Wheezing } & \multirow[t]{2}{*}{ Overall wheezing } \\
\hline & 1 year & 2 years & 3 years & 4 years & 6 years & \\
\hline \multicolumn{7}{|c|}{ Bed-sharing at 2 months } \\
\hline Model 2 & $0.95(0.81-1.12)$ & $0.99(0.82-1.20)$ & $1.04(0.83-1.30)$ & $0.99(0.78-1.25)$ & $1.00(0.75-1.31)$ & $0.98(0.89-1.08)$ \\
\hline \multicolumn{7}{|c|}{ Bed-sharing at 24 months } \\
\hline Model 1 & & & $1.35(1.05-1.75)$ & $1.56(1.19-2.04)$ & $1.71(1.26-2.33)$ & $1.51(1.29-1.79)$ \\
\hline
\end{tabular}

Data are presented as OR $(95 \% \mathrm{Cl})$ from generalised estimating equation models and represent the odds of wheezing (yes/no) for children who bed-share with their parents at 2 and 24 months of age. Bold indicates statistical significance $(p<0.05)$. Model 1 was adjusted for maternal educational level, age, smoking during pregnancy, and sex of the child. Model 2 was additionally adjusted for maternal body mass index, maternal psychological distress, breastfeeding, parity, child ethnicity, gestational age at birth, day care attendance, pet keeping and maternal history of atopy and asthma. The models for bed-sharing at 24 months were additionally adjusted for bed-sharing at 2 months. \# : $n=6160$.

Both directions of the bed-sharing-wheezing association were simultaneously examined in a cross-lagged model (figure 2). The strongest associations were between the two assessments of bed-sharing (OR 4.46, 95\% CI 3.63-5.49) and between the repeated assessments of wheezing, reflecting a strengthening association with increasing age (e.g. wheezing from 1 to 2 years: OR 6.35, 95\% CI 5.43-7.43; from 4 to 6 years: OR 13.9, 95\% CI 10.9-17.9). The lagged associations indicated that bed-sharing at 2 years was associated with an increased risk of wheezing at age 3, 4 and 6 years (e.g. OR for wheezing at 6 years 1.62, 95\% CI 1.09-2.41). Bed-sharing before the age of 2 years was not associated with subsequent wheezing, nor did wheezing predict bed-sharing.

\section{Discussion}

Bed-sharing decreased from roughly $20 \%$ in infancy to $10 \%$ in toddlerhood, which has been reported in previous studies [28-31]. Wheezing decreased from 30\% to $10 \%$ during the first 6 years of life, similar to findings from other cohorts [32]. We found no association between bed-sharing in early infancy (age 2 months) and wheezing in the first 6 years of life or a diagnosis of asthma at 6 years of age. Also, wheezing at age 1 and 2 years did not associate with bed-sharing practices at 24 months. By contrast, we found an association between bed-sharing in toddlerhood (age 24 months) and both wheezing and asthma at later ages.

TABLE 3 Associations of bed-sharing at 2 and 24 months with patterns of wheezing and asthma diagnosis ${ }^{\#}$

\begin{tabular}{ccc} 
& Wheezing pattern & Asthma" \\
\hline Early only & Late only & Persistent \\
$(1,2$ and 3 years $)$ & (4 and 6 years) & (1-6 years)
\end{tabular}

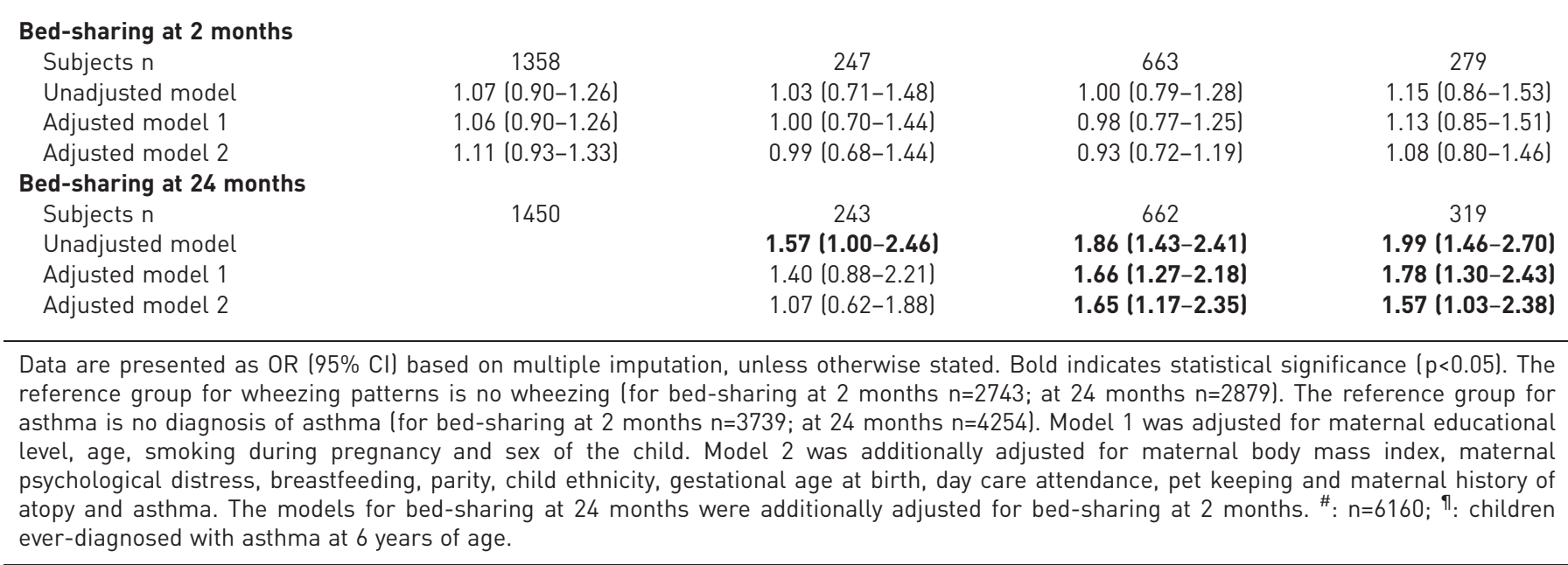




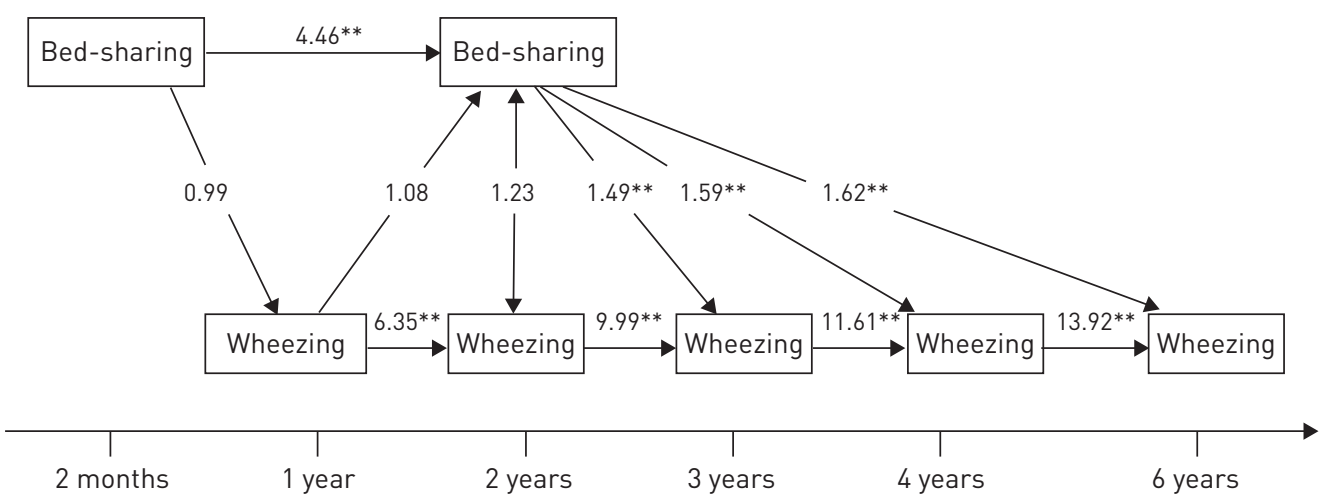

FIGURE 2 Cross-lagged model including lagged associations between repeated bed-sharing and wheezing measures. Values represent odds ratios. The model was adjusted for covariates. Covariates were regressed on baseline bed-sharing and wheezing. Model fit: Akaike Information Criterion: 33111 (adjusted), 33544 (unadjusted); Bayesian Information Criterion: 33407 (adjusted), 33665 (unadjusted). ${ }^{* *}: \mathrm{p}<0.01$.

Although the latter finding is in line with the increased risk theory [1-4], the finding that early bed-sharing did not associate with more wheezing or asthma suggests that a causal relationship is unlikely.

Studies on bed-sharing practices and asthma in early childhood have not been conducted previously, and the current study is the first, to our knowledge, to document this association. In this study, bed-sharing in early infancy was assessed before wheezing had been assessed, i.e. when the child was 2 months-old, which precludes reversed causality mechanisms. Our study also did not confirm a protective effect of bed-sharing practices on asthma [6-9], but it might be possible that bed-sharing parents are more attuned to their children's breathing and, therefore, more likely to report wheezing. Alternatively, bed-sharing at 24 months could be more common in families for whom child wheezing is perceived as problematic and leads to child sleep problems which in turn elicit bed-sharing. More night awakenings [13,33], worse sleep quality $[14]$ and sleepiness during the day $[25,34]$ have indeed been reported in samples of school aged and pre-adolescent children with asthma, but other studies did not find differences between asthmatic and nonasthmatic children $[35,36]$. In a single study on preschool children, no differences in sleep quality between asthmatic children and healthy controls were reported in the first four years of life [36]. In the current study, sleep problems experienced at the age of 18 months attenuated the effect of toddlerhood bed-sharing on asthma diagnosis at 6 years of age, but sleep problems did not attenuate the effect of toddlerhood bed-sharing on repeated assessments of later wheezing or on the persistent wheezing phenotype, suggesting that bed-sharing might indeed be a disease-specific parental monitoring practice rather than a reaction to the child's sleep problems.

Indeed, asthma symptoms are frequently experienced during night-time hours, and the parents of ill children are more vigilant [37], which could suggest that bed-sharing is a nocturnal monitoring practice, in which parents take their already wheezing children into the parental bed. However, our results did not show an association between early wheezing and later bed-sharing. They do indicate an association between bed-sharing in toddlerhood and later wheezing. These findings converge with the increased risk theory and suggest that it is less likely that wheezing precedes bed-sharing.

Childhood wheezing and asthma might partly be caused by both infectious and atopic mechanisms [38, 39]. In the current study, controlling for respiratory tract infections did not change the association between bed-sharing and wheezing or asthma outcomes, suggesting that the association cannot be explained by infectious mechanisms. Child inhalant allergy did attenuate the effect of bed-sharing at 24 months on asthma diagnosis, but it did not attenuate the effect on the repeated wheezing measures or the persistent wheezing phenotype. A history of inhalant allergy is an important risk factor for development of childhood asthma [40, 41], and our findings suggest that atopy could affect the development of asthma in bed-sharing families. However, previous studies also indicate that multiple features may interact in the expression of early wheezing, and the combination of these features (e.g. atopy and lung function) might determine the likelihood of persistence of symptoms into childhood [32]. Studies disentangling the complex effects of child sleep problems and atopy as risk factors in the development of asthma in bed-sharing children are needed [42].

Regardless of bed-sharing, the very frequent mother-infant contact in the first months of life adds to the complexity of the associations in the current study. The absence of an association between bed-sharing at 2 months and later wheezing possibly indicates that all children share microorganisms with their mothers 
in these first months of life, and that, according to the hygiene hypothesis [7], this early sharing of microorganisms at least temporarily protects infants from developing allergic diseases.

Many demographic and environmental factors also affect the development of childhood wheezing and asthma [41], and must be taken into account when modelling associations with family and crowding factors. In the first model, a small set of confounders was used, but even when controlling for a comprehensive set of confounders (as in the second model), the effect estimates remained significant, indicating a robust association between bed-sharing in toddlerhood and development of asthma.

Some strengths and limitations need to be considered. This study was embedded in a population-based prospective cohort with a large number of subjects who were followed from early fetal life onwards with detailed prospectively and repeatedly measured information on bed-sharing and wheezing, and a large number of potential confounders available [15]. Due to nonresponse not all mothers and children could be included in the analyses, and nonresponders more often had a lower socioeconomic position. This might have affected our findings, although the inclusion of a comprehensive set of confounding variables reduces the likelihood that results were biased. Furthermore, we imputed missing data to prevent possible selection bias, which minimised biased effect estimates due to selective response on measurements [43]. We added extra variables to our imputation model and performed 25 imputations, to optimise our imputations. Although the multiple imputation method has been suggested to be the preferable method to deal with missing data, we cannot exclude that residual confounding might have occurred. A limitation of our study is the lack of information on the use of inhalant asthma medication. However, wheezing prevalence was based on maternal reports using ISAAC questionnaires, a widely accepted and reliable method of assessing wheezing in epidemiological studies [44]. Bed-sharing practices were assessed with a single question at both time-points, indicating whether families regularly bed-share. Findings from a previous study using the same measurement converged with results from the bed-sharing literature [11]; however, in future studies bed-sharing practices should be assessed in more depth.

Our findings suggest that children who bed-shared in toddlerhood have higher odds of wheezing at 3-6 years of age, and higher odds of being diagnosed with asthma at 6 years of age. Children bed-sharing in infancy did not have higher odds of these outcomes. Early wheezing was not associated with bed-sharing. Therefore, in the current longitudinal study design with advanced statistical analyses we were able to disentangle the direction of the association between bed-sharing and respiratory outcomes. Further studies are needed to explore the effects of bed-sharing at later ages and to examine the underlying causal mechanisms.

\section{Acknowledgements}

The Generation R Study is conducted by the Erasmus Medical Center in close collaboration with the School of Law and Faculty of Social Sciences of the Erasmus University Rotterdam, the Municipal Health Service Rotterdam area, Rotterdam, the Rotterdam Homecare Foundation, Rotterdam and the Stichting Trombosedienst \& Artsenlaboratorium Rijnmond (STAR), Rotterdam. We gratefully acknowledge the contribution of general practitioners, hospitals, midwives and pharmacies in Rotterdam.

\section{References}

1 Trenholme A, Vogel A, Lennon D, et al. Household characteristics of children under 2 years admitted with lower respiratory tract infection in Counties Manukau, South Auckland. N Z Med J 2012; 125: 15-23.

2 Jackson S, Mathews $\mathrm{KH}$, Pulanić $\mathrm{D}$, et al. Risk factors for severe acute lower respiratory infections in children: a systematic review and meta-analysis. Croat Med J 2013; 54: 110-121.

3 Prietsch SO, Fischer GB, César JA, et al. Acute lower respiratory illness in under-five children in Rio Grande, Rio Grande do Sul State, Brazil: prevalence and risk factors [Doença respiratória aguda baixa em menores de cinco anos em Rio Grande, Rio Grande do Sul, Brasil: prevalência e fato]. Cad Saude Publica 2008; 24: 1429-1438.

4 Garenne M, Ronsmans C, Campbell H. The magnitude of mortality from acute respiratory infections in children under 5 years in developing countries. World Health Stat Q 1992; 45: 180-191.

5 Simoes EA. Environmental and demographic risk factors for respiratory syncytial virus lower respiratory tract disease. J Pediatr 2003:143: Suppl., S118-S126.

6 Cardoso MRA, Cousens SN, de Góes Siqueira LF, et al. Crowding: risk factor or protective factor for lower respiratory disease in young children?. BMC Public Health 2004; 4: 19

7 Strachan DP. Hay fever, hygiene, and household size. BMJ 1989; 299: 1259-1260.

8 Infante-Rivard C, Amre D, Gautrin D, et al. Family size, day-care attendance, and breastfeeding in relation to the incidence of childhood asthma. Am J Epidemiol 2001; 153: 653-658.

9 Wickens KL, Crane J, Kemp TJ, et al. Family size, infections, and asthma prevalence in New Zealand children. Epidemiology 1999; 10: 699-705.

10 Baddock SA, Galland BC, Taylor BJ, et al. Sleep arrangements and behavior of bed-sharing families in the home setting. Pediatrics 2007; 119: e200-e207.

11 Luijk MPCM, Mileva-Seitz VR, Jansen PW, et al. Ethnic differences in prevalence and determinants of motherchild bed-sharing in early childhood. Sleep Med 2013; 14: 1092-1099.

12 Koinis-Mitchell D, Craig T, Esteban CA, et al. Sleep and allergic disease: a summary of the literature and future directions for research. J Allergy Clin Immunol 2012; 130: 1275-1281. 
13 Chugh IM, Khanna P, Shah A. Nocturnal symptoms and sleep disturbances in clinically stable asthmatic children. Asian Pac J Allergy Immunol 2006; 24: 135-142.

14 Stores G, Ellis AJ, Wiggs L, et al. Sleep and psychological disturbance in nocturnal asthma. Arch Dis Child 1998; 78: 413-419.

15 Jaddoe VW, van Duijn CM, Franco OH, et al. The Generation R Study: design and cohort update 2012. Eur J Epidemiol 2012; 27: 739-756.

16 Asher MI, Keil U, Anderson HR, et al. International Study of Asthma and Allergies in Childhood (ISAAC): rationale and methods. Eur Respir J 1995; 8: 483-491.

17 Bisgaard $\mathrm{H}$, Hermansen MN, Buchvald F, et al. Childhood asthma after bacterial colonization of the airway in neonates. N Engl J Med 2007; 357: 1487-1495.

18 Sonnenschein-van der Voort AMM, Jaddoe VWV, van der Valk RJ, et al. Duration and exclusiveness of breastfeeding and childhood asthma-related symptoms. Eur Respir J 2012; 39: 81-89.

19 Martinez FD, Wright AL, Taussig LM, et al. Asthma and wheezing in the first six years of life. N Engl J Med 1995; 332: $133-138$.

20 Jansen PW, Saridjan NS, Hofman A, et al. Does disturbed sleeping precede symptoms of anxiety or depression in toddlers? The generation R study. Psychosom Med 2011; 73: 242-249.

21 Beurs ED. Brief Symptom Inventory, handleiding. PITS, Leiden, 2004.

22 Achenbach TM, Rescorla LA. Manual for the ASEBA Preschool Forms and Profiles. Burlington, University of Vermont Research Center for Children, Youth, and Families, 2000

23 Hays RD, Marshall GN, Wang EYI, et al. Four-year cross-lagged associations between physical and mental health in the medical outcomes study. J Consult Clin Psychol 1994; 62: 441-449.

24 Klebanoff MA, Cole SR. Use of multiple imputation in the epidemiologic literature. Am J Epidemiol 2008; 168: 355-357.

25 van Maanen A, Wijga AH, Gehring U, et al. Sleep in children with asthma: results of the PIAMA study. Eur Respir J 2013; 41: 832-837.

26 Guxens M, Sonnenschein-van der Voort AMM, Tiemeier H, et al. Parental psychological distress during pregnancy and wheezing in preschool children: the Generation R Study. J Allergy Clin Immunol 2014; 133: 59-67.

27 Forno E, Acosta-Pérez E, Brehm JM, et al. Obesity and adiposity indicators, asthma, and atopy in Puerto Rican children. J Allergy Clin Immunol 2014; 133: 1308-1314.

28 Willinger M, Ko CW, Hoffman HJ, et al. Trends in infant bed sharing in the United States, 1993-2000: the National Infant Sleep Position study. Arch Pediatr Adolesc Med 2003; 157: 43-49.

29 Arnestad M, Andersen M, Vege A, et al. Changes in the epidemiological pattern of sudden infant death syndrome in southeast Norway, 1984-1998: implications for future prevention and research. Arch Dis Child 2001; 85: $108-115$.

30 Blair PS, Ball HL. The prevalence and characteristics associated with parent-infant bed-sharing in England. Arch Dis Child 2004; 89: 1106-1110.

31 Blair PS, Heron J, Fleming PJ. Relationship between bed sharing and breastfeeding: longitudinal, population-based analysis. Pediatrics 2010; 126: 1119-1126.

32 Savenije OE, Granell R, Caudri D, et al. Comparison of childhood wheezing phenotypes in 2 birth cohorts: ALSPAC and PIAMA. J Allergy Clin Immunol 2011; 127: 1505-1512.

33 Desager KN, Nelen V, Weyler JJJ, et al. Sleep disturbance and daytime symptoms in wheezing school-aged children. J Sleep Res 2005; 14: 77-82.

34 Sadeh A, Horowitz I, Wolach-Benodis L, et al. Sleep and pulmonary function in children with well-controlled, stable asthma. Sleep 1998; 21: 379-384.

35 Ronchetti R, Villa MP, Matricardi PM, et al. Association of asthma with extra-respiratory symptoms in schoolchildren: two cross-sectional studies 6 years apart. Pediatr Allergy Immunol 2002; 13: 113-118.

36 Tirosh E, Scher A, Sadeh A, et al. Sleep characteristics of asthmatics in the first four years of life: a comparative study. Arch Dis Child 1993; 68: 481-483.

37 Tong A, Lowe A, Sainsbury P, et al. Experiences of parents who have children with chronic kidney disease: a systematic review of qualitative studies. Pediatrics 2008; 121: 349-360.

38 Klinnert MD, Nelson HS, Price MR, et al. Onset and persistence of childhood asthma: predictors from infancy. Pediatrics 2001; 108: E69

39 Wright AL. Epidemiology of asthma and recurrent wheeze in childhood. Clin Rev Allergy Immunol 2002; 22: 33-44.

40 Rochat MK, Illi S, Ege MJ, et al. Allergic rhinitis as a predictor for wheezing onset in school-aged children. J Allergy Clin Immunol 2010; 126: 1170-1175.

41 Morais-Almeida M, Gaspar Â, Pires G, et al. Risk factors for asthma symptoms at school age: an 8-year prospective study. Allergy Asthma Proc 2007; 28: 183-189.

42 Bloomfield SF, Stanwell-Smith R, Crevel RWR, et al. Too clean, or not too clean: the Hygiene Hypothesis and home hygiene. Clin Exp Allergy 2006; 36: 402-425.

43 Spratt M, Carpenter J, Sterne JAC, et al. Strategies for multiple imputation in longitudinal studies. Am J Epidemiol 2010; 172: 478-487.

44 Jenkins MA, Clarke JR, Carlin JB, et al. Validation of questionnaire and bronchial hyperresponsiveness against respiratory physician assessment in the diagnosis of asthma. Int J Epidemiol 1996; 25: 609-616. 